\title{
Investigation of Surface Roughness, Kerf Width and MRR on AISI D2 Steel Machined by Wire EDM
}

\author{
M. Shunmuga Priyan", J.D. Darwin \\ Department of Mechanical Engineering, Loyola Institute of Technology \& Science, India
}

Copyright $\subset 2017$ by authors, all rights reserved. Authors agree that this article remains permanently open access under the terms of the Creative Commons Attribution License 4.0 International License

\begin{abstract}
Engineering industry has made tremendous growth in its manufacturing fields in the last decade but still the modern machines are not utilized up to the desired level. Wire electrical discharge machining (WEDM) is one such sophisticated machining process used in industry, which is a high-speed cutting and high-precision machining to realize productivity and improved accuracy for all manufacturing parts. Optimisation of the operating parameters of WEDM will result in efficiency with regard to higher surface finish and maximum material removal rate. The present investigation of the cutting performance on die steel with different parameters such as pulse on time, pulse off time, servo voltage, wire feed, current and cutting speed were involved to determine by which using wire electric discharge machining(WEDM) process. The shape of the wire and base material dimensions of brass wire $0.25 \mathrm{~mm}$ diameter and AISI D2 steel with $100 \times 100 \times 10 \mathrm{~mm}$ were carried out. The cutting performance outputs considered in this study are material removal rate (MRR), Kerf width and surface roughness $(\mathrm{Ra})$. Experiments were carried out under Taguchi's $\mathrm{L}_{16}$ orthogonal array under different conditions of parameters. An optimal combination of WEDM parameters for proper machining of AISI D2 steel to achieve better surface roughness and Materials Removal Rate (MRR) is achieved in this investigation.
\end{abstract}

Keywords WEDM, Die Steel, MRR, Surface Roughness, Kerf Width, Optimization

\section{Introduction}

Electrical Discharge Machining (EDM) is a controlled metal-removal process that is used to remove metal by means of electric spark erosion. In this process an electric spark is used as the cutting tool to cut (erode) the work piece to produce the finished part to the desired shape. The metal-removal process is performed by applying a pulsating (ON/OFF) electrical charge of high-frequency current through the electrode to the work piece. This removes (erodes) very tiny pieces of metal from the work piece at a controlled rate. In WEDM process, a small diameter wire ranging from 0.05 to $0.25 \mathrm{~mm}$ is applied as the tool electrode. A DC power supply delivers high-frequency pulses of electricity to the wire and the work piece. The study of Parveen et al. [1] machining gap between the wire and work piece is flooded with deionised water, which acts as the dielectric medium. Moreover, it was investigated Puri and Bhattacharyya [2] that WEDM, material is eroded from the work piece by a series of discrete sparks occurring between the work piece and the wire separated by a stream of die electric fluid, which is continuously fed to the machining zone. Liao et al. [3] reported that the WEDM process factors affecting in the condition of parameters which is need the settings for the various wire parameters and optimal conditions. The most significant process parameters which affect the machining performance are MRR, SR in WEDM process reported by Miller et al. [4] and the properties affecting the Konda et al. [5] WEDM performance due to work piece material and di-electric fluid, machining parameters and component geometry. Wang and Lin [6], investigated by Taguchi method and $\mathrm{L}_{18}$ orthogonal array to obtain the polarity, peak current, pulse duration, duty factor, rotary electrode rotational speed, and gap load voltage in order to explore the material removal rate, electrode wear rate, and surface roughness. The influence of each variable and optimal processing parameter is obtained through design of experiments and ANOVA to improve the process of the WEDM is a complex machining process controlled by a large number of process parameters such as the pulse duration, discharge frequency and discharge current. Any slight variation in the process parameters will affect the machining performance measures such as MRR, SR which are the two of the most significant aspects of WEDM operation. Sarkar et al. [7] performed experiments using Titanium-Auminide alloy as work material and then formulated mathematical models to predict the cutting speed, SF and dimensional deviation as the function of different control parameters. Authors reported that Ramakrishnan and 
Karunamoorthy [8], three response characteristics, e.g., and MRR, SR and wire wear ratio for a WEDM process and determined the optimal process settings. This is done by optimization of multiple response signal-to-noise (MRSN) ratio, which is the logarithmic transformation of the sum of weighted normalized quality loss of individual response variable. Several attempts were made to perform a parametric study from time to time, Han et al. [9], Jin et al. [10], Kanlayasiri et al. [11], Liao et al. [12]. Mahapatra and Patnaik [13] established the relationship between various process parameters and responses using non-linear regression analysis and then employed genetic algorithm to optimize the WEDM process. Chiang and Chang [14] optimized the surface roughness (SR) and Material Removal Rate (MRR) of a WEDM process for $\mathrm{Al}_{2} \mathrm{O}_{3}$ particle reinforced material based on Grey Relational Analysis (GRA) method. Levy and magi [15] have compared the influence of material properties of different steels on machining characteristics, but only qualitatively. It is extremely difficult to conclude and pinpoint definite physical quantity that can fully reflect the material properties for WEDM, and use it to predict machining characteristics Dibitonto et al. [16], Dijck [17], Eubank et al. [18]. Hsue et al. [19], developed a model to estimate the MRR during geometrical cutting by considering wire deflection with transformed exponential trajectory of the wire. Spur and schonbeck [20] designed a theoretical model and studied the influence of the work piece material and the pulse type properties on the WEDM of a work piece with an anodic polarity. Han et al. [21] developed a simulation system, which accurately reproduces the discharge phenomenon of WEDM. The system also applies an adaptive control, which automatically generate an optimal machining condition for high precision WEDM. The aim of this work a study of material removal mechanism in Wire Electro Discharge Machining (WEDM) process and optimization of performance characteristics has been undertaken keeping into consideration the following problems such as pulse on time, pulse off time, voltage, current and other machining parameters.

\section{Experimental Details}

\subsection{Process Parameters Selection}

The experiments were carried out on a Wire Electro Discharge Machine (WEDM) ELECTRONICA "ECOCUT" of M/S Electronic Machine Tools Ltd. Installed at Precision Engineering Lab of Manufacturing Engineering Department, College of Engineering, Anna University, Guindy, Chennai-25, Tamil Nadu, and India. The discussions are related to the measurement of WEDM experimental Parameters like material Removal Rate (MRR), kerf width and Surface Roughness are presented in the following. The results obtained are analyzed for the selection of an optimal combination of WEDM parameters for proper machining of die steel to achieve better surface roughness and Materials Removal Rate (MRR). Refer Table 1.

Table 1. Process parameters of Wire-EDM process

\begin{tabular}{|c|c|c|}
\hline SL.No & Parameters & Range \\
\hline 1 & Wire Material & Diffused Brass Wire \\
\hline 2 & Wire Size $(\mathrm{mm})$ & $\varnothing 0.25$ \\
\hline 3 & Wire tension $(\mathrm{gm})$ & 1600 \\
\hline 4 & Dielectric & Deionised water \\
\hline 5 & Table feed rate $(\mathrm{mm} / \mathrm{min})$ & 80 \\
\hline 6 & Work Piece & D2 die steel \\
\hline
\end{tabular}

\subsection{Selection of the Work Piece}

These materials are used in extreme load conditions such as hot work forging, extrusion etc. The applications of these materials are varied such as manufacturing of punching tools, mandrels, mechanical press forging die, plastic mould and die-casting dies, air craft landing gears, shafts, space craft's etc. The materials composition has been displayed below refer Table.2.

Table 2. Typical compositional ranges for grade $\mathrm{D} 2$ die steel

\begin{tabular}{|c|c|c|c|c|c|c|c|}
\hline $\mathrm{W} \%$ & $\mathrm{C}$ & $\mathrm{Va}$ & $\mathrm{Si}$ & $\mathrm{Mg}$ & $\mathrm{Fe}$ & $\mathrm{Cr}$ & $\mathrm{Mo}$ \\
\hline 100 & 1.5 & 0.9 & 0.2 & 0.3 & 84 & 12 & 0.8 \\
\hline
\end{tabular}

\subsection{Material Removal Rate (MRR)}

For WEDM, MRR is a desirable characteristic and it should be as high as possible to give least machine cycle time leading to increased productivity. In the present study MRR is calculated as

$$
\begin{gathered}
M R R=\frac{\text { Weight loss due to machining }}{(\text { Density of the material } \times \text { machining time })} \\
\mathrm{MRR}=\mathrm{K} \times \mathrm{t} \times \mathrm{Vc} \times \mathrm{p},
\end{gathered}
$$

Where, $\mathrm{K}=$ kerf width $\mathrm{mm}, \mathrm{Vc}=$ cutting speed $\mathrm{m} / \mathrm{s}, \rho=$ density of material $\mathrm{kg} / \mathrm{m}^{3}, \mathrm{t}=$ thickness of material $\mathrm{mm}$.

\subsection{Surface Roughness}

With contact-type surface roughness instruments, a stylus tip makes direct contact with the surface of a sample. The detector tip is equipped with a stylus tip, which traces the surface of the sample and electrically detects the vertical motion of the stylus. To precisely measure delicate shapes and roughness with a contact-type surface roughness tester, the radius of the stylus tip must be as small as possible with low contact pressure.

\subsection{Taguchi Design}

Dr. Genichi Taguchi is the foremost proponent of robust 
parameter design, which is an engineering method for product or process design that focuses on minimizing variation and/or sensitivity to noise. When used properly, Taguchi designs provide a powerful and efficient method for designing products that operate consistently and optimally over a variety of conditions. Taguchi proposed several approaches to experimental designs that are called "Taguchi Methods." These methods utilize two-, three-, four-, five-, and mixed-level fractional factorial designs. Taguchi refers to experimental design as "off-line quality control" because it is a method of ensuring good performance in the design stage of products or processes. The process parameters and their levels selected for final experimentation has been depicted in Table 3.

Table 3. Factors and their levels for $\mathrm{D} 2$ die steel material

\begin{tabular}{|c|c|c|c|c|}
\hline Factor & Parameter & Level 1 & Level 2 & Level 3 \\
\hline A & Gap Voltage V & 40 & 50 & 60 \\
\hline B & Pulse on Time $\mu \mathrm{s}$ & 10 & 8 & 6 \\
\hline C & Pulse off Time $\mu \mathrm{s}$ & 2 & 4 & 6 \\
\hline D & Applied Current A & 2.1 & 1.9 & 1.8 \\
\hline
\end{tabular}

\section{Results and Discussion}

The influences on MRR, Surface Roughness and kerf width is analyzed based on factors like discharge current, pulse duration, diameter of brass wire, is most important with help of Taguchi method. The response table for MRR Surface Roughness and kerf width are shown in Table 4 along with the input factors. In this investigation, the effects on material removal rate (MRR), surface roughness, and kerf width are determined by varying WEDM essential parameters such as peak current (A), Pulse on time (Ton), Pulse off time (Toff) and gap voltage (V).The experimental data were transferred to grey relational grade and were assessed using analysis of variance (ANOVA) for determining the significant and optimal combinational levels of machining parameters to achieve multiple performance characteristics. So in WEDM optimal machining parameters were established for achieving high MRR, good surface roughness and kerf width for difficult to machine materials. In this work, grey relational analysis was adopted to evaluate the multiple performance characteristics of MRR, kerf width and Surface Roughness for D2 die steel materials. The grey relational grade refers to the overall evaluation of experimental data for the performance characteristics using L16 orthogonal array which is represented in the Table 4. From this above array table, we have chosen the orthogonal array of L-16 based on 5 factors such as pulse on time, pulse off time, peak current, wire material, work piece material. Minitab 17 software was used for graphical analysis of the obtained data.

Table 4. Response table

\begin{tabular}{|c|c|c|c|c|c|c|c|c|c|c|}
\hline Sl.No & $\begin{array}{c}\mathrm{T}(\mathrm{on}) \\
(\mu \mathrm{s})\end{array}$ & $\begin{array}{c}\mathrm{T}(\mathrm{off}) \\
(\mu \mathrm{s})\end{array}$ & $\begin{array}{c}\text { Wire feed } \\
(\mathrm{m} / \mathrm{mim})\end{array}$ & $\begin{array}{c}\text { Voltage } \\
(\mathrm{V})\end{array}$ & $\begin{array}{c}\text { Current } \\
(\mathrm{A})\end{array}$ & $\begin{array}{c}\mathrm{M} / \mathrm{c} \text { speed } \\
(\mathrm{mm} / \mathrm{min})\end{array}$ & $\begin{array}{c}\text { Time } \\
(\mathrm{min})\end{array}$ & $\begin{array}{c}\text { Kerf } \\
\text { width } \\
(\mathrm{mm})\end{array}$ & $\begin{array}{c}\text { Ra } \\
(\mu \mathrm{m})\end{array}$ & $\begin{array}{c}\text { MRR } \\
\left(\mathrm{mm}^{3} / \mathrm{min}\right)\end{array}$ \\
\hline 1 & 10 & 2 & 2 & 40 & 2.1 & 1.9 & 9.18 .56 & 0.291 & 1.72 & 42.57 \\
\hline 2 & 10 & 4 & 4 & 50 & 1.9 & 1.4 & 12.06 .86 & 0.272 & 1.41 & 29.32 \\
\hline 3 & 10 & 6 & 6 & 60 & 1.8 & 1.1 & 15.05 .86 & 0.281 & 1.26 & 23.8 \\
\hline 4 & 10 & 8 & 8 & 70 & 1.1 & 0.7 & 24.10 .99 & 0.286 & 2.13 & 15.41 \\
\hline 5 & 8 & 2 & 6 & 50 & 1.9 & 1.5 & 11.15 .10 & 0.268 & 1.37 & 30.95 \\
\hline 6 & 8 & 4 & 8 & 40 & 1.9 & 1.6 & 10.59 .13 & 0.292 & 1.53 & 35.97 \\
\hline 7 & 8 & 6 & 2 & 70 & 1.3 & 0.8 & 21.47 .72 & 0.266 & 2.86 & 16.38 \\
\hline 8 & 8 & 8 & 4 & 60 & 1.5 & 0.9 & 18.37 .69 & 0.265 & 1.51 & 18.36 \\
\hline 9 & 6 & 2 & 8 & 60 & 1.5 & 1.2 & 14.52 .80 & 0.291 & 1.29 & 26.88 \\
\hline 10 & 6 & 4 & 6 & 70 & 1.3 & 0.8 & 21.49 .16 & 0.282 & 4.06 & 17.37 \\
\hline 11 & 6 & 6 & 4 & 40 & 1.7 & 1.3 & 13.20 .48 & 0.283 & 1.6 & 28.32 \\
\hline 12 & 6 & 8 & 2 & 50 & 1.2 & 1.1 & 15.59 .30 & 0.287 & 1.83 & 24.3 \\
\hline 13 & 4 & 2 & 4 & 70 & 1.3 & 0.8 & 21.51 .35 & 0.295 & 2.17 & 18.17 \\
\hline 14 & 4 & 4 & 2 & 60 & 1.4 & 1 & 17.53 .70 & 0.292 & 1.36 & 22.48 \\
\hline 15 & 4 & 6 & 6 & 50 & 1.2 & 1.1 & 16.37 .11 & 0.304 & 1.62 & 25.74 \\
\hline 16 & 4 & 8 & 8 & 40 & 1.5 & 1.1 & 16.02 .30 & 0.306 & 1.16 & 25.91 \\
\hline
\end{tabular}


Figure 1 is represented by means of graph between times (on) and number of trails conducted on die steel material. From the graph revealed that to increase in kerf width in which increase in time at various parameters. Depends upon the input parameters active on while machining time may be possible to vary the cutting width of materials are called as kerf width. The effectiveness of the entire process normally depends on input process parameters such as pulse on time, pulse off time, peak current, dielectric fluid rate, wire feed, and wire tension. The important machining responses include material removal rate (MRR), surface roughness (Ra) and Kerf (width of cut. At the same time given smooth input parameters in the WEDM process has been showed in better surface roughness in die steel materials represented in the Figure 2. Surface roughness is greatly affected by pulse on time, peak current and cutting speed in WEDM. Among these pulse on time is found to be the most significant parameter affecting the surface roughness [22].

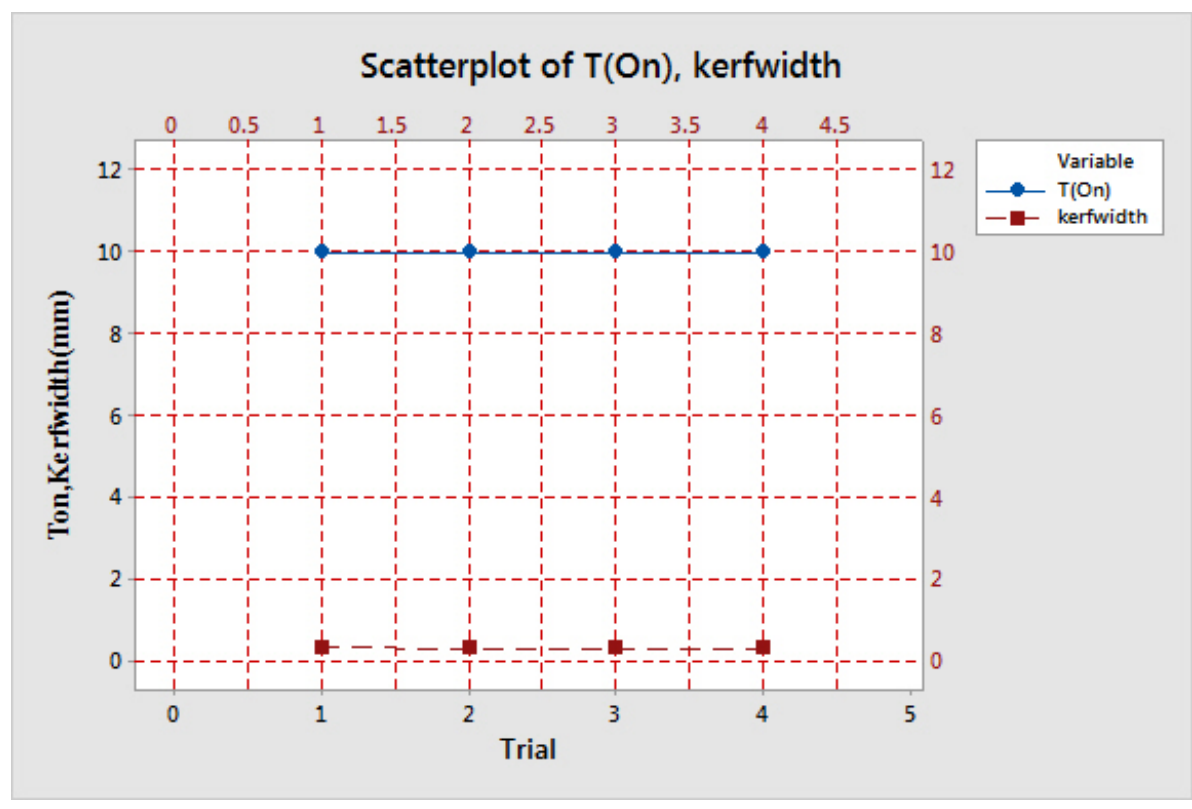

Figure 1. Graph plot between $\mathrm{T}(\mathrm{on})$ and response variables

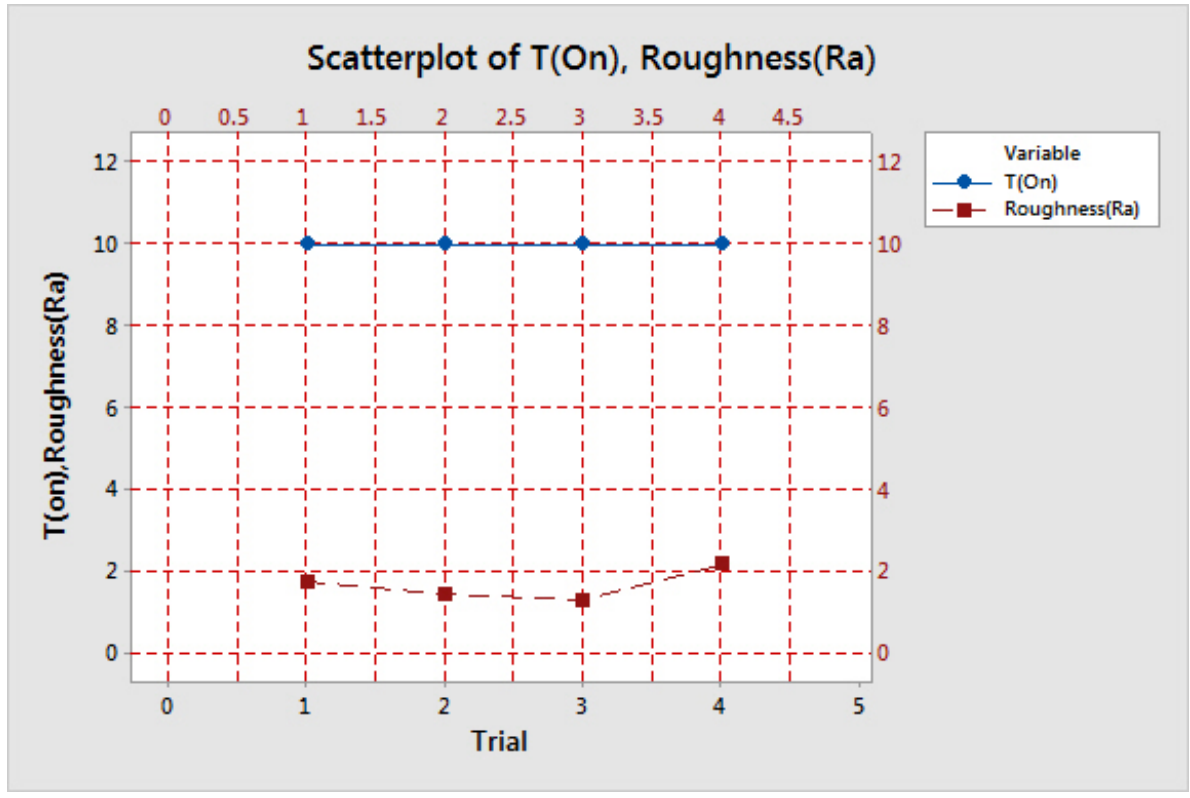

Figure 2. Graph plot between surface roughness and response variables 
When the pulse on time increased in showed on plot of the results showed sometimes decrease in MRR at this condition. The WEDM process is not stable because of various condition of parameters may be voltage and current in the process as shown in Figure 3. The material erodes by means WEDM process which is attribute from the work piece normalise in discrete sparks between the work and the tool electrode immersed in the liquid dielectric medium. These electrical discharges melt and vaporize minute amounts of the work material, which are then ejected and flushed away by the dielectric fluid. MRR directly increases with increase in pulse on time (Ton) and peak current (IP) while decreases with increase in pulse off time (Toff) and servo voltage (SV). The results of optimization indicate that the MRR and surface finish are influenced more by pulse peak current, pulse duration, pulse off period and wire feed than by flushing pressure and wire tension. Results also indicate that the surface quality decreases as the MRR increases and they vary almost linearly. Material removal rate increases with proportionate increasing the pulse duration due increase pulse energy.

Kerf is one of the important performance measures in WEDM. Kerf is the measure of the amount of the material that is wasted during machining. It affects the dimensional accuracy of the finished part. Kerf width appearance measured on work piece depends on gap voltage, pulse on time, pulse off time, wire feed and flushing pressure. It is measured in millimetres $(\mathrm{mm})$. It is the measure of the amount of the material that is wasted during machining and determines the dimensional accuracy of the finishing part. For present experiments kerf width has been measured. Figure 4, represented in using of the $\mathrm{T}$ (off) input parameters in machining process is to finally show of kerf width of die steel materials. Figure 5 plot slightly increased linear graph when operate machining in $\mathrm{T}$ (off) mode operations.

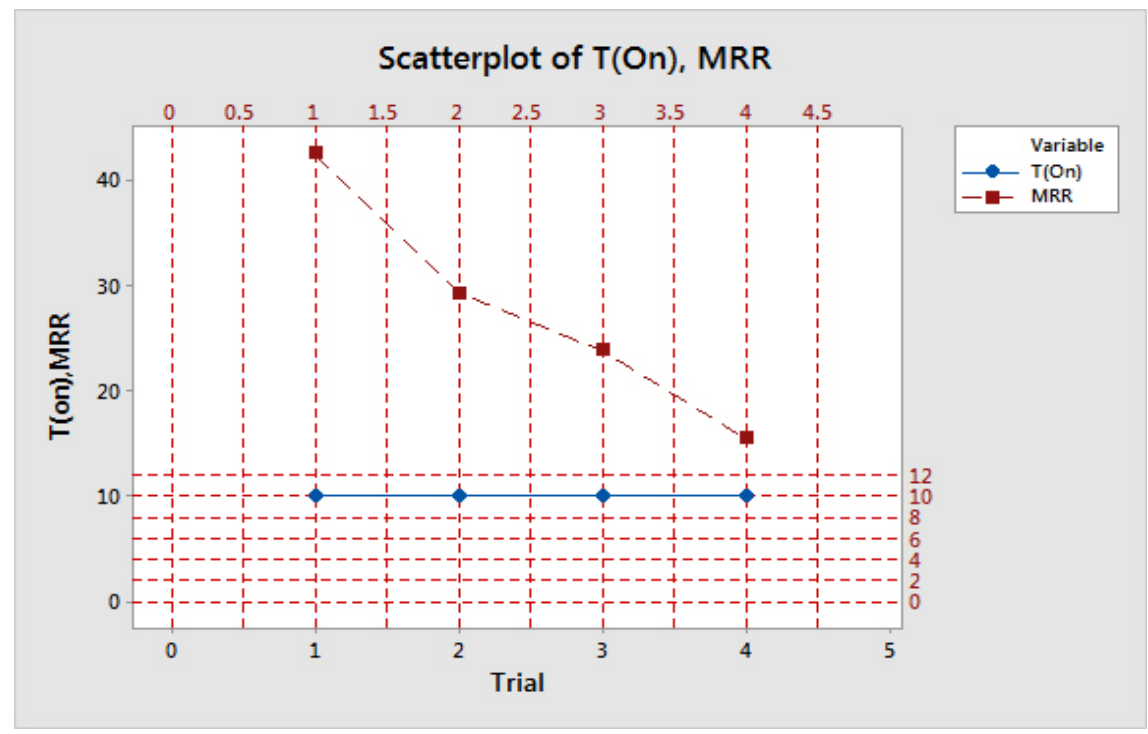

Figure 3. Graph plot between MRR and response variables

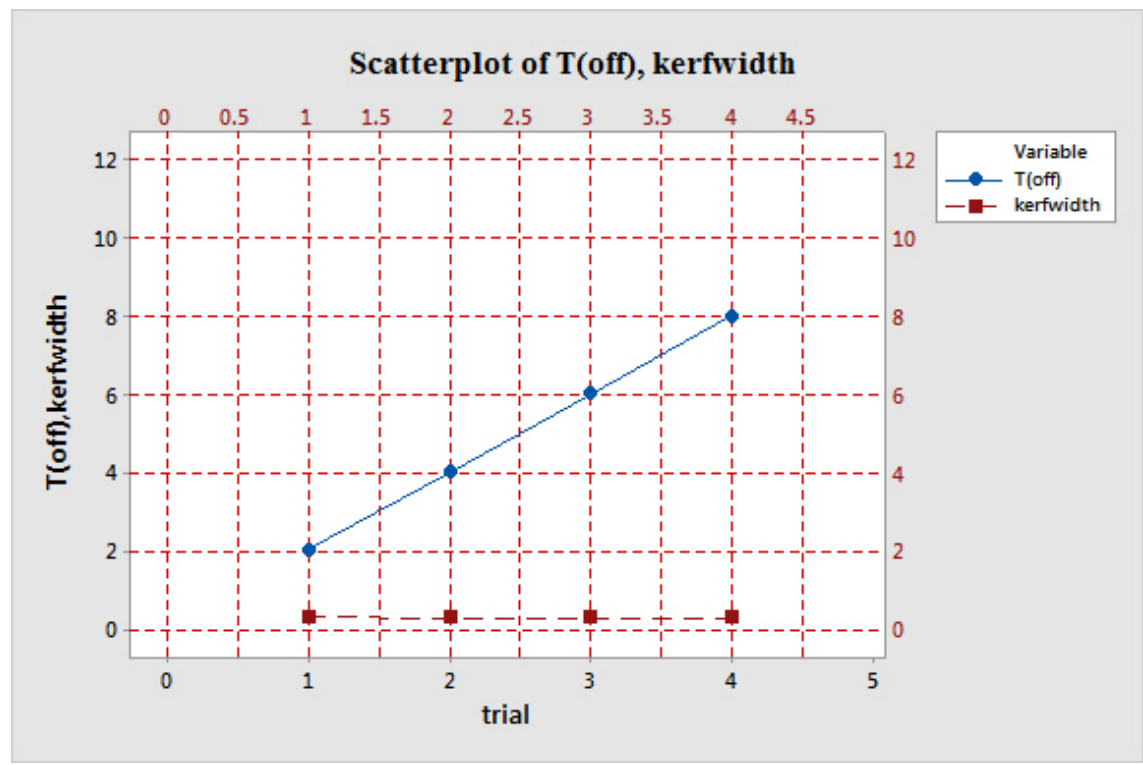

Figure 4. Graph plot between Kerf and response variables 


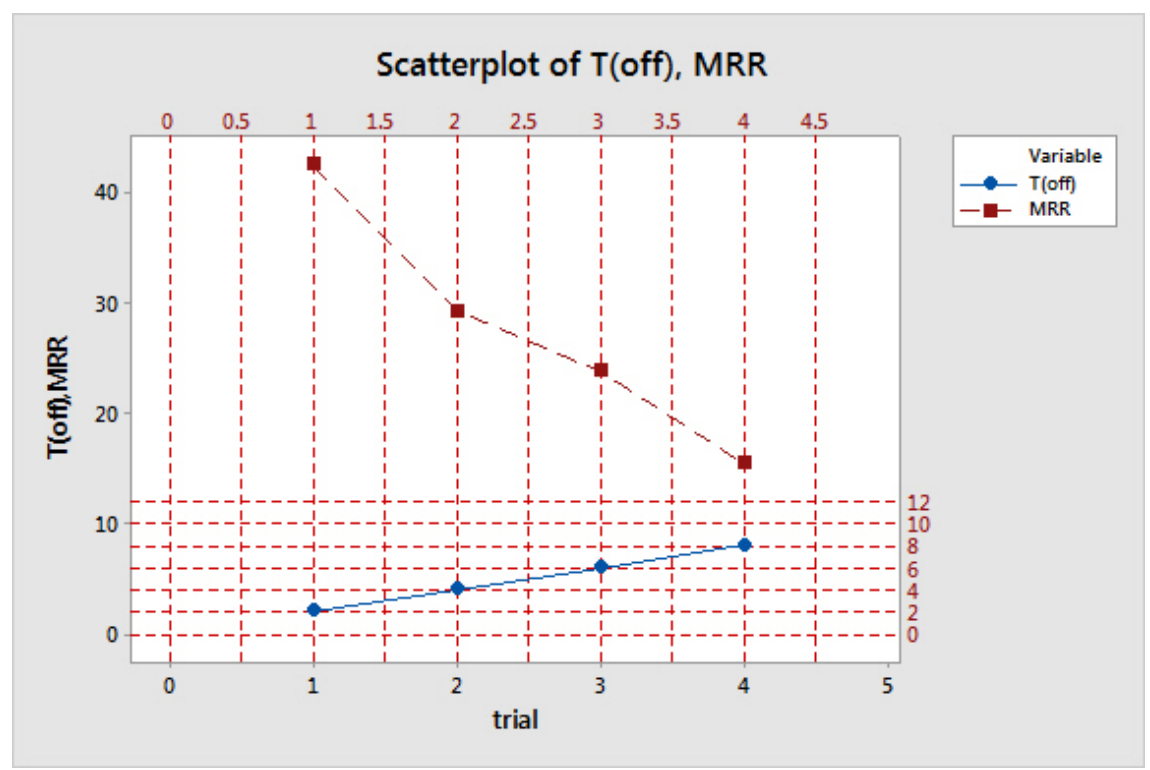

Figure 5. Graph plot between $\mathrm{T}(\mathrm{off})$ and response variables

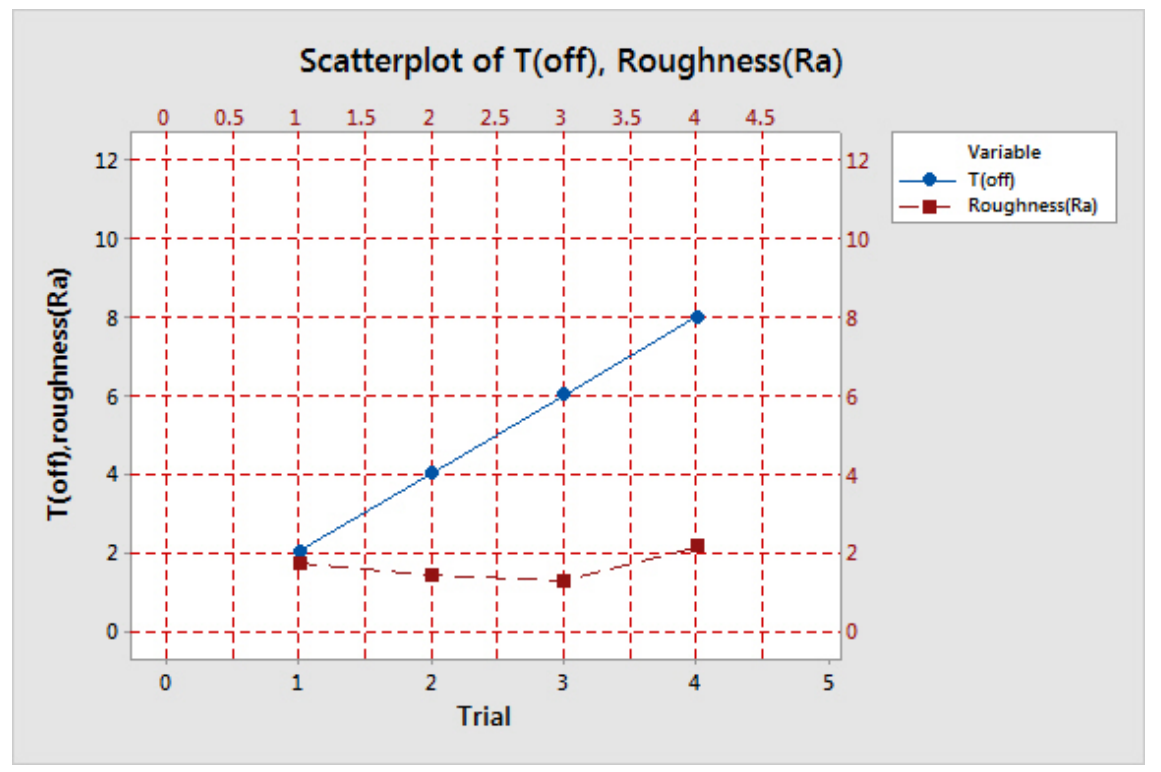

Figure 6. Graph plot between surface roughness and response variables

Figure 6 shows the surface roughness decreases upon increasing Pulse on Time and increasing upon increasing Pulse off time and Peak Current. Based on the input parameters, we can achieve minimal Surface Roughness (SR). MRR increases upon variables Pulse off Time and Peak Current. By choosing the input parameters are optimizing, we can achieve minimal increasing wear rate under controlled condition. Surface roughness increases with increase in current density. As the current increases surface of the final product becomes more and more rough. With the current increases from 1.9 ampere to 2.9 ampere surface roughness nominal value increases from 1.83 to $3.1 \mu \mathrm{m}$. Also, current and surface roughness relationship can be graphed as shown in Figure 6. As the pulse on time 35 increases, the surface roughness increases due to increase in the frequency of sparking. In the other words, double sparking and localized sparking become more frequent as the pulse on time increases. Double sparking produces a poor surface roughness. Pulse on time followed by peak current has significant effect on surface roughness. Increase in these parameters produce poor surface finish. Kumar et al confirmed in wire electric discharge machining of D2 die steel the larger pulse on time and peak current will cause to double sparking which increase surface roughness in machining.

The grey relational grade represents the level of correlation between the reference sequence and the comparability sequence, the greater value of the grey relational grade means that the comparability sequence has a stronger correlation to the reference sequence. Based on grey relational grade value were given by average response in table. In this table, higher grey relational grade from each 
level of factor indicates the optimum level. The Pulse on time $(10 \mu \mathrm{s})$, Pulse off time (4 $\mu \mathrm{s})$ and Servo voltage (60 volts) respectively. The above graph between Pulse on Time, Pulse off Time with determine the MRR and Surface roughness value increased and decrease based on optimization parameters. In this parameters were determine the characterization of materials (D2 Steel) and high material removal rate also identified. The effects of discharge current, pulse duration, pulse frequency, wire speed, wire tension and dielectric flow rate in wire electric discharge machining of D2 die steel using on coated copper wire with $0.25 \mathrm{~mm}$ diameter on surface roughness and material removal rate. It indicated that factors like discharge current, pulse duration, dielectric flow rate and their interactions plays a significant role in surface roughness and material removal rate.

The effects of plots (Figure 8) represented in the characteristics of wire feed, voltage and current in which used in the process of wire EDM. Moreover, the chart has revealed that decreasing $\mathrm{T}$ (off), simultaneously increase current while the discharge at the machining. The signal and noise ratio is determined by Analysis of Variance (ANOVA) concept has represented by the table 4 , also significance of the various process parameters were involved in which the output of kerf width and surface roughness. The response table 4 shows the average of response characteristic such as MRR, surface roughness and kerf width. The performance of the materials was determined in which using of electrical discharging process at which variance of different parameters conditions. Figure 8 it can be seen that the conditions of voltage and current characteristic and further variation of different input such as pulse on time, pulse off time, peak current, servo voltage and servo feed result is produced minimum surface roughness and good MRR was carried out. In the Taguchi method, the term "signal" represents the desirable value (mean) for the output characteristic and the term "noise" represents the undesirable value (S.D) for the output characteristics. Therefore, the $\mathrm{S} / \mathrm{N}$ ratio is the ratio of the mean to the S.D. S/N ratio is used to measure the quality characteristic deviating from the desired value. The $\mathrm{S} / \mathrm{N}$ ratio $\eta$ is defined as 3 . Nominal the Better:

$$
\begin{aligned}
& \frac{s}{N}=-10 \log \left(\frac{1}{n}\right) \sum_{i=1}^{n} \frac{1}{y^{2}} \\
& \frac{s}{N}=-10 \log \left(\frac{1}{n}\right) \sum_{i=1}^{n} y^{2}
\end{aligned}
$$

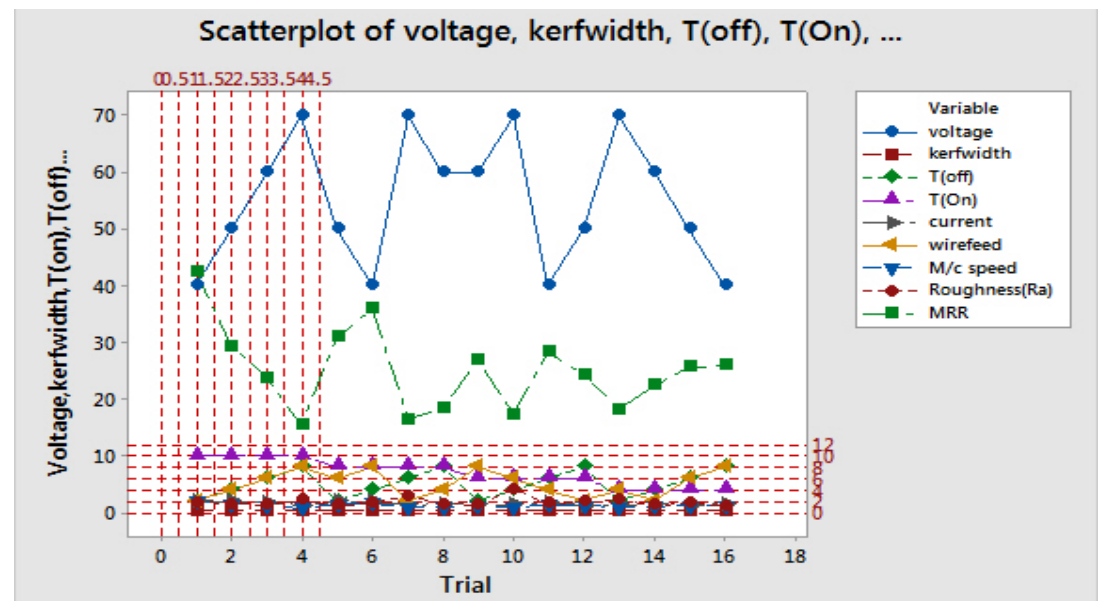

Figure 7. Comparision chart of Wire-EDM Parameters

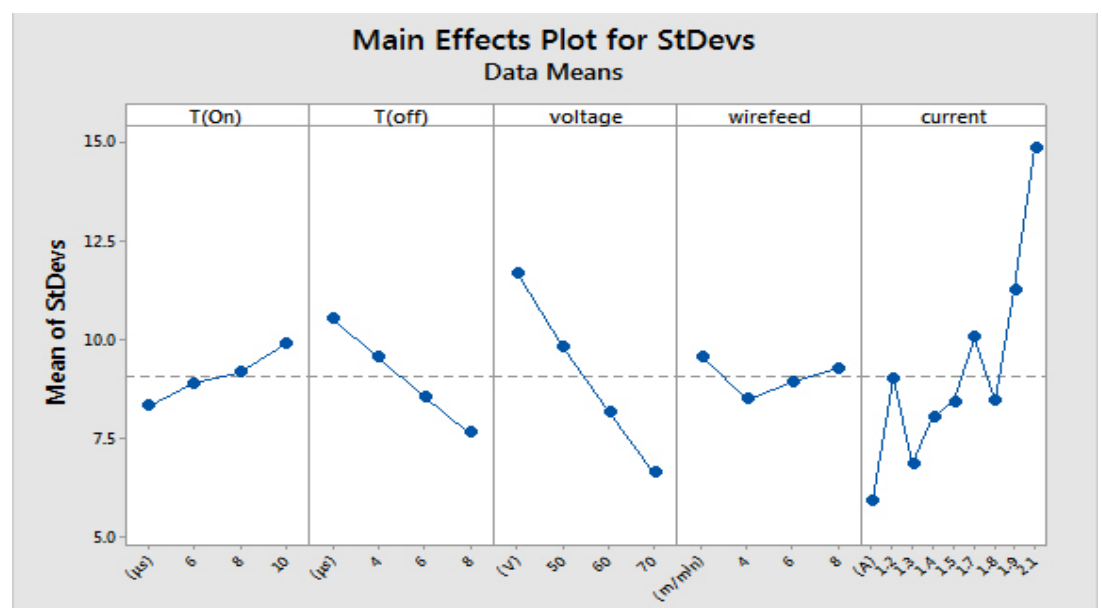




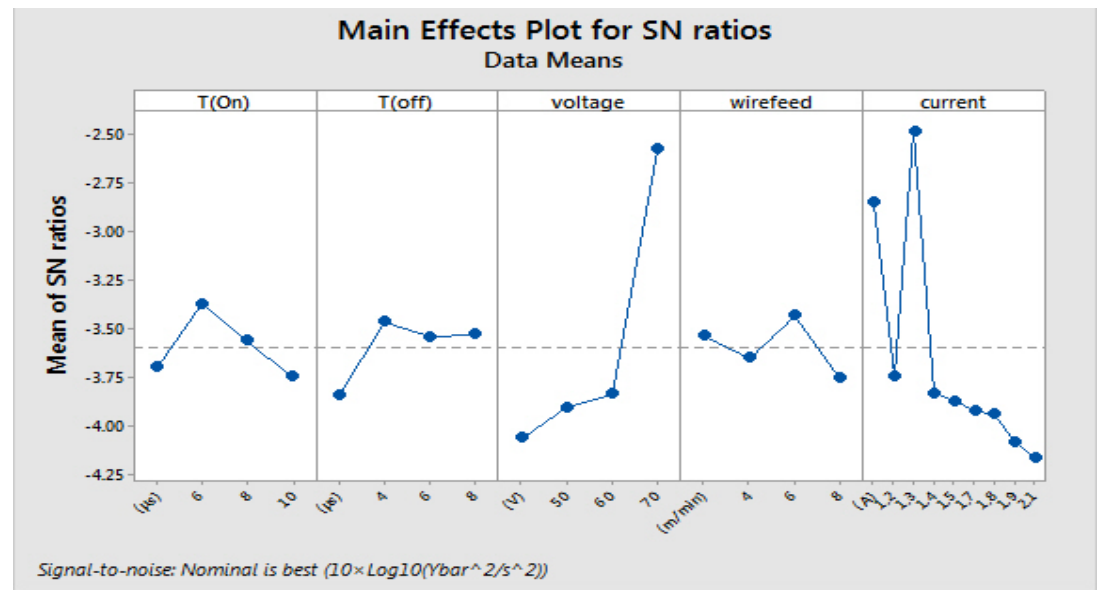

Figure 8. Effects plot for standard deviation and $\mathrm{S} / \mathrm{N}$ ratio

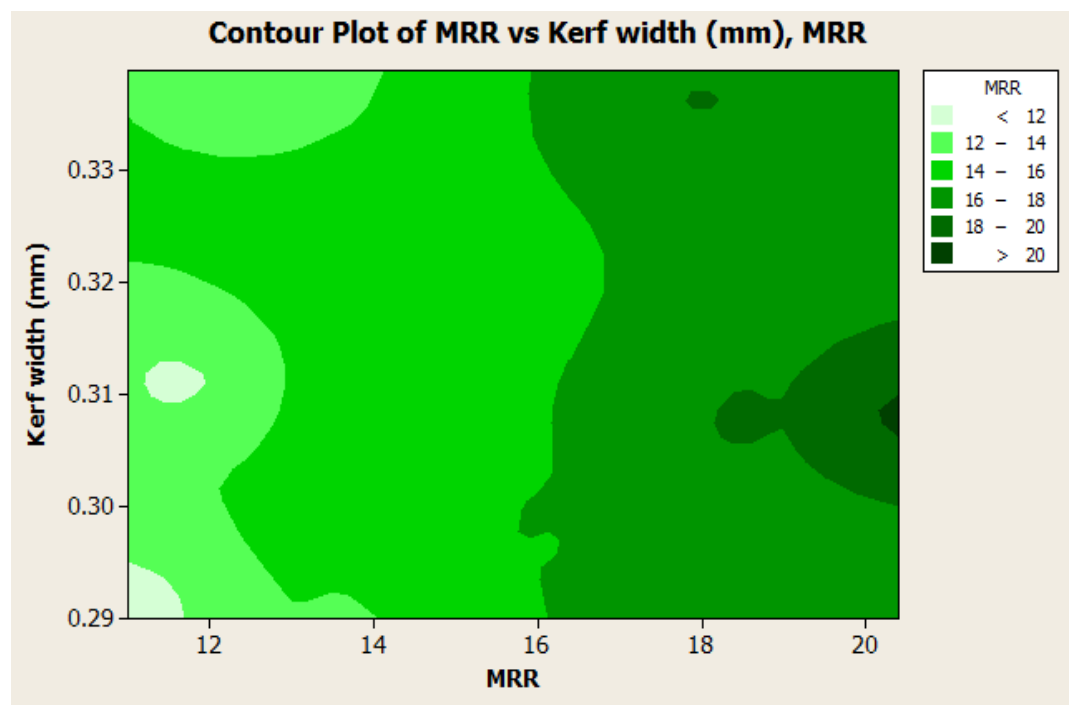

Figure 9. Shows Analysis of variance on MRR and Kerf Width

\section{Surface Plot of sl.no vs MRR, kerfwidth}

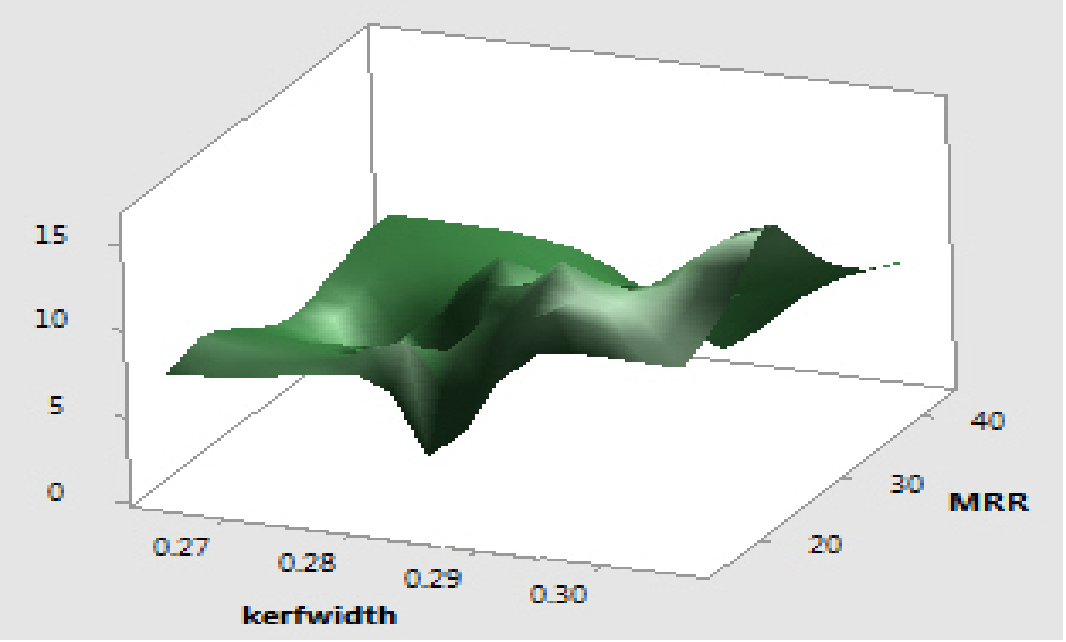

Figure 10. 3D contour plot of Kerf Width Vs MRR 
From Figure 9, it can be seen that for a particular value of input parameter the corresponding range of occurrence of kerf width can be determined and vice versa. It is established optimization techniques was revealed that give better performance results by which machining in the EDM process. The experimental results were confirmed to achieve the both MRR and surface roughness at increasing current and decreasing voltage, if the condition of machining performance. The Figure 10shows express with the analysis of variance between MRR and Kerf width. Finally, the taguchi's techniques is to investigated the parameters like pulse on time, pulse off time, peak current, servo voltage and servo feed on MRR and surface roughness on die steel using Wire-cut EDM process.

Figure 11 shows small gap of cutting by wire under parameter at this room condition. According to ANOVA the most significant parameters with respect to Kerf width are discharge voltage (A), capacitance (B), feed rate (C) interaction of voltage From the Figure, it can be concluded that Kerf width can be achieved using low discharge energy and constant stable discharge circumstance. This will be improving the dimensional accuracy and reduction of material removal while cutting a corner in micro-machined components. It is also observed that increase in the voltage leads to an increase in discharge energy and hence Kerf Width (KW) increases. Similarly, the KW tends to increase with increase in capacitance and also at some point $\mathrm{KW}$ decreases. Figure 11 shows the two-dimensional contour plot of voltage and capacitance when feed rate remains fixed velocity at this conditions.

The shows the 16 number of trail specimen investigated against surface roughness and kerf width. Normally, the kerf width value has been produced significantly in the various cutting parameters in WEDM process. Depends upon the parameters were achieved different kind of value between 0.265 and $0.306 \mathrm{~mm}$ has obtained in the EDM process.
Similarly the corresponding roughness value also varied at the condition of input parameters. The surface roughness were calculated in the 16 specimen is noted in the range of 1.16 and 4.06 microns significantly. Due to the condition of speed, feed, depth of cut, servo voltage and current parameters value were changed while machining operation in the condition of surface value is varied in the WEDM process.

\section{Conclusions}

In this work, experiments were carried out for material removal rate, surface roughness and KERF width by selection of optimal parameters such as, pulse on time, pulse off time and servo voltage. 16 experimental readings were taken for all variables to conduct the parametric study. Finally it can be concluded that: Grey relational analysis is done to find out optimal parameter levels. After grey relational analysis, it is found that pulse on time at level $4(8 \mu \mathrm{s})$, pulse off time at level $4(6 \mu \mathrm{s})$, servo voltage at level 4 (70volts) are the best process parameter for the MRR, KERF width and Surface roughness. The behaviour of optimal parameters for objective response depends on significant parameters and its percentage contribution changes. By increasing Pulse on time generates more spark energy due to increase in electric supply. Increasing pulse on time has various effects on parameters MRR, Kerf width and surface roughness $(\mathrm{Ra})$. When the voltage increases, surface Roughness also increases resulting in crater with broader and deeper characteristics.MRR decreases with increase of pulse off time while surface roughness $(\mathrm{Ra})$ reduces. During $\mathrm{T}_{\text {off }}$ time flushing of removed material takes place which is an important function. Servo voltage has little effect on surface roughness $\left(R_{a}\right)$ and kerf width but having more effect on MRR.
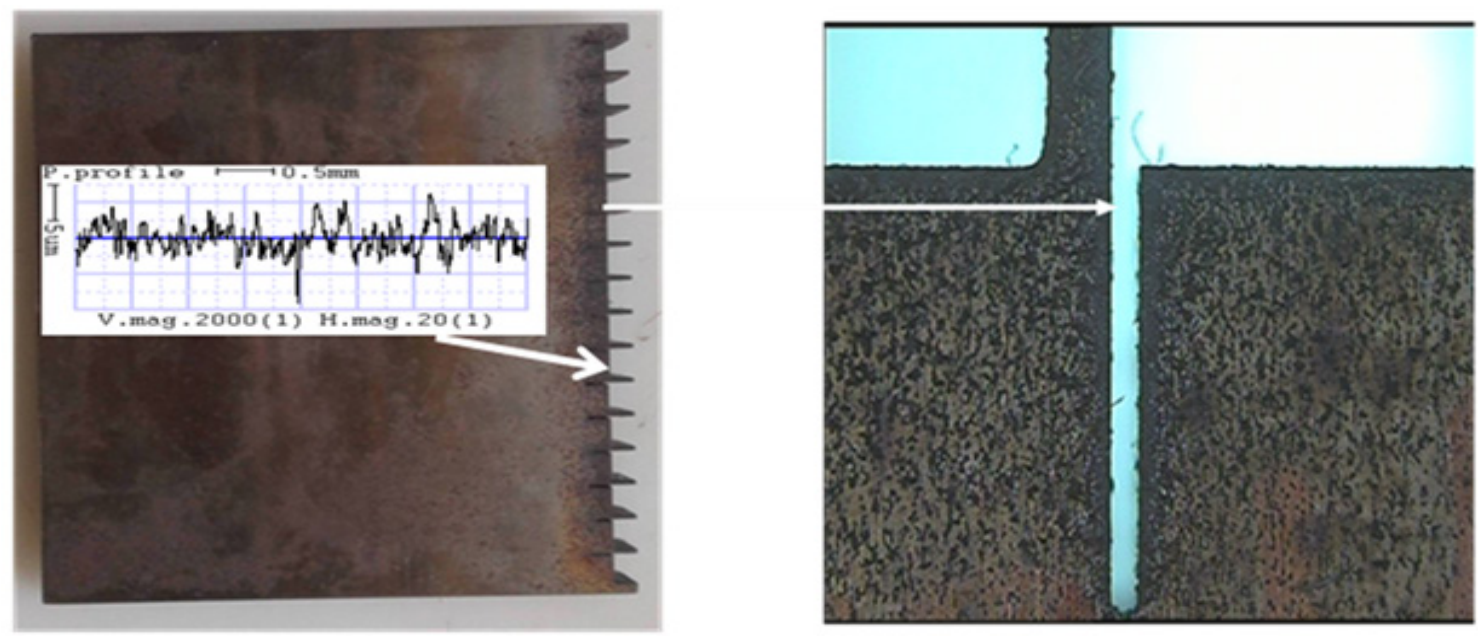

Figure 11. Shows Kerf width by VMS image 


\section{REFERENCES}

[1] Parveen Kr. Saini, Mukesh Verma, Experimental Investigation of Wire-EDM Process parameters on MRR of Ti-6al-4v Alloy, International Journal of Innovative Technology and Exploring Engineering, 2014, Vol.4, no.5. pp. $16-20$.

[2] Puri, A.B. and Bhattacharyya, B., "An analysis and optimization of the geometrical in accuracy due to wire lag phenomenon in WEDM", International Journal of Machine Tools and Manufacture, Vol.43, 2003, pp. 151-159.

[3] Liao, Y.S., Huang, J.T and Su, H.C. "A study of machining parameters optimization of wire electrical discharge machining", Journal of Materials Processing technology, Vol.71, 1997, pp. 487-493.

[4] Miller, S.F., Shih, A.J and Qu, J. "Investigation of the spark cycle on material removal rate in wire electrical discharge machining of advanced materials", International journal of Machine Tools \& Manufacture, Vol. 44, 2004, pp. 391-400.

[5] Konda, R.J., Rajurkar, K.P., Bishu, R.R., Guha, A. and Parson, M., "Design of experiments to study and optimize process performance", International Journal of Quality Reliability Management, Vol.16, no.1, 1999, pp. 56-71.

[6] Wang, K., Gelgel, H.L., Wang, Y., Yuan, Q and Fung, M., “ A hybrid intelligent method for modeling the EDM process", International Journal of Machine Tool Manufacture, Vol. 43, 2003, pp. 995-999.

[7] Sarkar, S., Sekh, M., Mitra, S. and Bhattacharyya, B. "Modeling and optimization of wire electrical discharge machining of $\gamma$-TiAl in trim cutting operation", Journal of Material Processing Technology, Vol. 205, 2008, pp. 376-387.

[8] Ramakrishnan, R. and Karunamoorthy, L., "Modeling and multi-response optimization of Inconel 718 on machining of CNC WEDM process", Journal of Materials Processing Technology, Vol.207, 2008, pp. 343-349.

[9] Han, F., Jiang, J and Dingwen, Yu. "Influence of machining parameters on surface roughness in finish cut of WEDM", International Journal of Advanced Manufacturing Technology, Vol. 34, 2007, pp.538 - 546.

[10] Jin, Y., Kesheng, W., Tao, Y. and Minglun, F., “ Reliable multi-objective optimization of high speed WEDM process based on Gaussian process regression", International Journal of Machine Tools and Manufacture, Vol. 48, 2008, pp. 47-60.

[11] Kanlayasiri, K. and Bonmung, S. "An investigation on effects of wire EDM machining parameters on surface roughness of newly developed DC53 die steel", Journal of Materials Processing Technology, Vol. 187-188, 2007, pp.26-27.

[12] Liao, Y.S., Huang, J.T. and Chen, Y.H. "A study to achieve a fine surface finish in Wire-EDM", Journal of Materials Processing Technology, Vol. 149, 2004, pp. 165-171.

[13] Mahapatra, S.S. and Patnaik, A. "Optimization of wire electrical discharge machining (WEDM) process parameters using Taguchi method", International Journal of Advanced Manufacturing Technology, Vol. 34, 2007, pp.911-925.

[14] Chiang, C.K. and Chang, F.P., "Optimization of the WEDM process of particle-reinforced material with multiple performance characteristics using grey relational analysis", Journal of Materials Processing technology, Vol. 180, 2006, pp. 96-101.

[15] Levy, G.N and Maggi, F., "WED mach inability comparison of different steel grades", Ann CIRP, vol. 39, 1990, pp.183-185.

[16] Dibitonto, D.D., Eubank, P.T., Patel, M.R. and Barrufet, M.A., "Theoretical models of the electrical discharge machining process -1: a simple cathode erosion model", Journal of Applied Physics, Vol. 66, 1989, pp. 4095-4103.

[17] Dijck, F.V. "Physico-mathematical analysis of the electro discharge machining process", Ph.D. Thesis Katholieke Universiteit te Leuven around, 1972.

[18] Eubank, P.T., Patel, M.R., Barrufet, M.A. and Bozhusrt, B., "Theoretical models of the electrical discharge machining process - III: The variable mass, cylindrical plasma model", Journal of Applied Physics, Vol. 73, no.1, 1993, pp. 7900-7909.

[19] Hsue, W.J., Liao, Y.S. and Lu, SS., "Fundamental geometry analysis of wire electrical discharge machining in corner cutting", International Journal of Machine Tools and Manufacture, Vol. 39, 1999, pp. 651-667.

[20] Spur, G. and Schonbeck, J., "Anode erosion in wire EDM - a theoretical model", Annals of the CIRP, Vol.42, no.1. 1993, pp. 253-256.

[21] Han.F., Jiang, J and Dinwen, Yu. "Influence of machining parameters on surface roughness in finish cut of WEDM", International Journal of Advanced Manufacturing Technology, Vol. 34, 2007, pp. 538-546. 